\title{
Protective effect of enzymatic hydrolyzate of Chlorophytum comosum (L.) against experimental toxic liver injury in Wistar rats at the age of two years
}

\author{
David A. Areshidze ${ }^{1}$, Lyudmila D. Timchenko ${ }^{2}$, Maria A. Kozlova ${ }^{1}$ \\ ${ }^{1}$ Center of Cell Biology and Applied Biotechnology, Moscow State Regional University, Moscow, Russian Federation \\ ${ }^{2}$ North Caucasian federal university, Stavropol, Russian Federation
}

\section{Email address:}

Nihilist78@mail.ru(D. A. Areshidze)

\section{To cite this article:}

David A. Areshidze, Lyudmila D. Timchenko, Maria A. Kozlova. Protective Effect of Enzymatic Hydrolyzate of Chlorophytum Comosum (L.) against Experimental Toxic Liver Injury in Wistar Rats at the Age of Two Years. American Journal of Bioscience and Bioengineering. Vol. 1, No. 4, 2013, pp. 49-54. doi: 10.11648/j.bio.20130104.11

\begin{abstract}
Researches of age-dependent changes of liver functions and their correction with the use of various biologically active substances are an important issue of modern biomedicine. Investigation of the influence of the enzymatic hydrolyzate of Chlorophytum comosum (L.) on the liver of rats at the age of two years at its experimental toxic damage showed that the substrate has expressed a pronounced hepatoprotective effect. Under its influence morphological changes in the rat liver induced by $\mathrm{CCl}_{4}$ are much less pronounced than in the controls. There are also less significant deviations from normal levels of Alanine transamilase (ALT), Alanine transaminase AST and Total Bilirubin in blood plasma. Information analysis of the state of the organ indicates that the level of adaptation and regeneration opportunities of the liver of rats treated with an enzymatic hydrolyzate of Chlorophytum comosum (L.) is significantly higher than at the liver of rats with experimental toxic liver damage without the use of studied substrate. Histopathological analysis confirmed the alleviation of liver damage in connection with use of enzymatic hydrolyzate of Chlorophytum comosum (L.)
\end{abstract}

Keywords: Liver, Hydrolizate, Hepatotoxicity, Hepatocyte, Chlorophytum Comosum (L.)

\section{Introduction}

Liver disease is one of the most pressing public health problems around the world, because the liver is one of the central organs to ensure homeostasis. Hepatic injury is associated with distortion of various metabolic functions $[6,10,16,17]$.

Researches of age-dependent changes of liver functions and their correction with the use of various biologically active substances are an important issue of modern biomedicine. Aging of liver is characterized by alterations of liver biology and by a reduction of many functions which are important for the maintenance of body homeostasis. The main dysfunctions include appearance of enlarged hepatocytes, violation of liver regeneration, development of hepatic steatosis, alterations in the hepatic sinusoid $[5,9,12,13,21,22]$.

The elderly are predisposed to a variety of diseases, which contribute to a marked increase in morbidity in this subpopulation. The incidence of liver disease increases in the elderly, but the cellular and subcellular perturbations that underlie this suspected predisposition to pathology remain unresolved. Several age-related changes have been documented, including a decline of liver volume, an increase in the hepatic dense body compartment (lipofuscin), moderate declines in the Phase I metabolism of certain drugs, shifts in the expression of a variety of proteins and diminished hepatobiliary functions [19].

In modern scientific literature there are few reports about the healing properties of the plant Chlorophytum comosum (L.). It is shown that the leaves of this plant have a high sorption characteristics with respect to formaldehyde, carbon monoxide, benzene, trichlorethylene, phenols and other compounds [4,3]. By chemical analysis of the enzymatic hydrolyzate of Chlorophytum comosum in its composition was found DL - ornithine monohydrochloride having desintoxication and hepatoprotective action $[7,8,11,15,20,23]$.

Previous studies have revealed the hepatoprotective effect of the enzymatic hydrolyzate of Chlorophytum comosum (L.) on the liver of rats with experimental toxic 
damage in young and middle age [2].

These facts allow us to consider this hydrolyzate as a biologically active substance having hepatoprotective properties, which allows authors to keep focused on the study of the effect of the hydrolyzate regenerative potential of the Male Wistar Albino rats liver in old age. To test the hypothesis about the effectiveness of bio-stimulation, we carried out a study which purpose was to examine the severity of liver damage while taking $\mathrm{CCl}_{4}$ and enzymatic hydrolyzate of Chlorophytum comosum (L.).

\section{Materials and Methods}

\subsection{Collecting of Plant Material}

The fresh aerial parts of the C. Comosum plant were collected in Moscow state regional University botanical garden. The collected plant samples were washed thoroughly with running tap water and were used to prepare an enzymatic hydrolyzate.

\subsection{Preparation of Hydrolyzate}

The starting substance in an amount of $0,333 \mathrm{~kg}$ was washed thoroughly under running tap water (previously placing in gauze). The washed raw material was placed in a glass container with 1.0 liter $(1: 3)$ of tap water heated to a temperature of $(45 \pm 1){ }^{\circ} \mathrm{C} . \mathrm{Na}_{2} \mathrm{CO}_{3}$ was added to the mixture to $\mathrm{pH} 8,2-8,3$ ( $\mathrm{pH}$ was defined on phenolphthalein). Then were added $0.15 \mathrm{~kg}$ of crushed pancreas of cattle. Then container was covered by tightly cotton-gauze pad with parchment and placed in a thermostat at $(45 \pm 1){ }^{\circ} \mathrm{C}$. Kept for 10 days, shaking during the first day every 15 minutes to 5 minutes, and in the following days every two hours to 5 minutes. The dynamics of the enzymatic process was defined on the increase of the content of amino nitrogen. At the ninth or tenth day increase stops and hydrolyzate is left for the night in the switched-off thermostat. Then the hydrolyzate was filtered through a filter paper. In the filtrate was added chloroform in the ratio $2 \%$ to the total amount, the substance was placed in a glass flask with the rubber stopper and was stored at a temperature from 2 to $8^{\circ} \mathrm{C}$.

\subsection{Animals}

Male Wistar Albino rats of body weights ranging from 150 to $170 \mathrm{~g}$ were used in the study. Age of the animals was 2 years old. The animals were fed with standard pellet diet and water ad libitum. They were maintained in controlled environment (12:12 h light/dark cycle) and temperature $\left(30 \pm 2^{\circ} \mathrm{C}\right)$. All the animal experiments were performed according to the compliance with the EC Directive 86/609/EEC and with the Russian law regulating experiments on animals.

\subsection{Toxity Studies}

Based on previous studies $[1,2]$ the dose of enzymatic hydrolyzate of Chlorophytum comosum (L.) at the concentration of $6 \mathrm{mg} / \mathrm{kg}$.bw was chosen for the experiments.

\subsection{Treatment Design}

150 animals (Male Wistar Albino rats) were randomized and divided into three groups on fifty animals in each group. Group I served as intact control. Animals in Group II were inhaled by carbon tetrachloride to $2 \mathrm{~min}$. per day for 6 days (control group). Rats in Group III were inhaled carbon tetrachloride to 2 min a day for 6 days, but at the same time treated with drinking enzymatic hydrolyzate of Chlorophytum comosum (L.) at the concentration of 6 $\mathrm{mg} / \mathrm{kg}$.bw (experimental group).

Selection of carbon tetrachloride $\left(\mathrm{CCl}_{4}\right)$ as an agent acting on the liver is caused by the fact that this substance is a direct liver poison, widely used in experimental medicine and biology. Selecting of the liver-toxic and exposure method is determined by the fact that the use of carbon tetrachloride under this scheme provides the appearance and development of reversible changes in liver at tissue and organ level.

\subsection{Assessment of Hepatoprotective Activity}

\subsubsection{Biochemical Examinations}

For the 7th day of experiment, blood samples were collected by direct cardiac puncture using light ether anesthesia. Blood was separated by centrifuging at 2500 rpm for $20 \mathrm{~min}$ and used for analysis of AST, ALT, Total Bilirubin by using standard Kits (PLIVA-Lachemia Diagnostica, Chech Republic, Brno).

\subsubsection{Histopathological Analysis}

A small portion of liver was taken and fixed in to $10 \%$ formaldehyde. After several treatments for dehydration in alcohol, sections having $5 \mu \mathrm{m}$ thickness were cut and stained with hematoxylin and eosin and histopathological analysis was carried.

To detect apoptotic cells semi-thin sections $(3 \mu \mathrm{m})$ were stained with methylene blue-azure II with afterstain by fuchsin. All stained sections were embedded in balsam.

\subsubsection{Determination of Mitotic, Apoptotic and Necrotic Index}

At hematoxylin and eosin stained sections were determined mitotic and necrotic cells. At sections stained by methylene blue-azure II with afterstain by fuchsin were determined apoptotic cells. Visualization was performed using a microscope Nicon 500L at $900 \times$ magnification. Studied was made for 5 fields of view on each section.

Apoptotic index was calculated by the formula [14]:

$$
\mathrm{AI}=\mathrm{N}_{\mathrm{a}} / \mathrm{N} \text {, }
$$

where $\mathrm{N}_{\mathrm{a}}$ - the number of apoptotic cells; $\mathrm{N}$ - total number of cells in the test population.

The mitotic index was calculated by the formula: 
$\mathrm{MI}=\mathrm{N}_{\mathrm{m}} / \mathrm{N}$,

where $\mathrm{N}_{\mathrm{m}}$ - number of mitosis; $\mathrm{N}$ - total number of cells in the test population.

Necrotizing index calculated by the formula:

$$
\mathrm{NI}=\mathrm{N}_{\mathrm{n}} / \mathrm{N} \text {, }
$$

where $\mathrm{N}_{\mathrm{n}}$-of necrotic cells; $\mathrm{N}$ - total number of cells in the test population.

\subsubsection{Morphometric Studies}

Volume of the nuclei of hepatocytes was measured by image analyzer "Videotest" at hematoxylin and eosin stained sections.

\subsection{Studies of the Information Condition of the System of the Liver}

We carried out a breakdown of the aggregate of the measured volumes of hepatocyte nuclei into classes.

Based on the concept of information in a tissue system as the displaying of the diversity of morphology and function of the process for assessing the information status of organs and tissues have been proposed and tested the such indicators - information morphological capacity $\left(\mathrm{H}_{\max }\right)$, information morphological entropy $(\mathrm{H})$, information morphological organization (S), the relative morphological entropy (h) and redundancy (R) [5]. In this case, the baseline characteristics, which were used to calculate these parameters, can vary widely (the linear dimensions of the structures, their number, etc.). In our study was defined the volume of the nuclei of hepatocytes.

Information morphological capacity $\mathrm{H}_{\max }$, which means the maximum structural diversity, calculated by formula [5]:

$$
\mathrm{H}_{\max }=\log _{2} \mathrm{n},
$$

where $\mathrm{n}$ - number of classes.

Next, we made the calculation of the real structural diversity $\mathrm{H}$. Real structural diversity is the parameter that clearly illustrates the degree of determinism of morphofunctional system in time and space [5].The calculation was made using the formula:

$$
\mathrm{H}=-\Sigma \mathrm{P}_{\mathrm{i}} \log _{2} \mathrm{Pi},
$$

where $\Sigma P_{i}$ is the sum of probabilities of stay of the measured parameter of cells in a one of existing classes; $\log _{2} P_{i}-\operatorname{logarithm}$ of the probability of staying in one of the possible classes. In this case, the value of Pi is defined as the classical probability [5].

Knowing the maximum and actual structural diversity, we can calculate the organization of the system (S), the difference between the maximum possible and the real structural diversity (implemented structural diversity). This parameter, in our opinion, displays the state of the system adaptability to date. To determine the value of this parameter is used the formula [5]:

$$
\mathrm{S}=\mathrm{H}_{\max }-\mathrm{H} .
$$

It is necessary to consider that when $\mathrm{H}=\mathrm{H}_{\max }$, the system is deterministic, but such relation to the vast majority of permissible is possible only in theory.

Then we determined the coefficient of relative entropy of the system, or (the coefficient of compression of information) $h$ by formula [5]:

$$
\mathrm{h}=\mathrm{H} / \mathrm{H}_{\max } \text {. }
$$

High levels of relative morphological entropy provide evidence of the disorder of the system and significantly reducing of its structural integrity [5].

The coefficient of the relative organization of the system (redundancy factor) $\mathrm{R}$ is given by [5]:

$$
\mathrm{R}=\left(\mathrm{S} / \mathrm{H}_{\max }\right) \times 100 \% \text {. }
$$

With these data, the researcher has the opportunity to calculate the equivocation of the system (the value of reliability) $\boldsymbol{e}[5]$ :

$$
\boldsymbol{e}=\left(\mathrm{H}_{\mathrm{p}}-\mathrm{H}_{\mathrm{n}}\right) / \mathrm{H}_{\max },
$$

where $H_{n}$ - real structural diversity in normal, $H_{p}$ - real structural diversity in pathology.

\subsection{Statistical Analysis}

Values are expressed as mean $( \pm \mathrm{SD})$. The statistical analysis was performed using one-way analysis of variance (ANOVA). The statistical difference determined using repeated measures analysis of variance or paired Student $t$ tests. A p value of $<0.05$ was considered statistically significant.

\section{Results}

\subsection{Effects of Enzymatic Hydrolyzate of Chlorophytum Comosum (L.) on Histopathology}

At the pathomorphologic examination of the liver of rats exposed to carbon tetrachloride was found by us that the organ of animals had a red color, sometimes with yellow or gray tint. About $27 \%$ of rat liver was spotty. The organs were loose, easily torn, the cut oozing blood. The histological study noted a pronounced diskomplexation of hepatic beams. Hepatocytes were swollen and their cytoplasm was cloudy, the boundaries of the cells were not clear, the nuclei were also swollen, bright, with blurred outlines. In hepatocytes clearly observed clear vacuoles. When stained with Sudan-III in $65 \%$ of cases in the vacuoles of hepatocytes revealed lipids. In rat liver hepatocytes detached state granular dystrophy. The vessels of the liver in different parts of the cut were unevenly expanded and filled with blood, in the field of triads were observed the signs of mild perivascular mesenchymal reaction.

In a number of cases are observed the connective tissue layers, thickened and infiltrated by small cells, significant in the field of triads. Blood vessels (central vein capillaries) 
in the liver are extended (hyperemia of blood vessels), the permeability of the walls of vessels for the blood cells is increased, the focal hemorrhage is observed. Among the cells is observed a large number of white blood cells, the macrophages. In hepatocytes there are a large number of vacuoles, including lipid, as evidenced by coloring with Sudan - III. The individual cells are very large and in fact are a continuum vacuole.

In $85 \%$ of cases are showed multiple foci of necrosis in different sizes, in which the structural elements of the individual cells are not rendered, and the liver tissue is a homogeneous structureless mass. In $45 \%$ of cases are noted extensive necrosis.

The observed changes indicate the development of typical toxic liver disease at animal subgroups. However, at some rats were established characteristic of the micro-focal alterative inflammation. A significant proportion of rats had typical signs of acute toxic hepatitis with high intensity of tissue damage (hepatitis alterative). Some animals had severe steatosis with defined necrotic component.

At the use of the hydrolyzate of Chlorophytum comosum with the simultaneous inhalation by $\mathrm{CCl}_{4}$, pathological changes in the liver are much less serious. Thus, in the liver of all animals remain beams and lobular structure. In this case, a few pockets of malnutrition alternate with areas represented with dual-core and intact hepatocytes (signs of recovery) or hepatocytes in a condition of the initial stage of granular dystrophy, fatty degeneration occurs in $24 \%$. Also, there are substantially less hepatocytes in a condition of a necrosis. It is noted the absence of focal hemorrhages, capillaries are moderately bloodshot, and there are no signs of swelling, and reduces the permeability of vessels which were registered in the group without the use of the hydrolyzate. Vessels in the triads are moderately dilated. In this case, $36 \%$ of hepatocytes have small vacuoles.

\subsection{Effects of Enzymatic Hydrolyzate of Chlorophytum Comosum (L.) on MI, AI and NI}

For the liver of intact rats we found the MI equal to 5.35 $\pm 0.34 \%$, AI $-1.55 \pm 0.26 \%$, and NI was $0.88 \pm 0.09 \%$. The value of MI in the liver of animals of the control group was $1.90 \pm 0.19 \%$, AI $-1.01 \pm 0.2 \% \mathrm{NI}-9.90 \pm 0.31 \%$. Application of enzymatic hydrolyzate of Chlorophytum comosum (L.) in experimental toxic injury of the liver leads to the MI of $4.75 \pm 0.21 \%$, AI $-2.80 \pm 0.16 \%$, NI $4.3 \pm 0.18 \%$. (Fig. 1).

\subsection{Effects of Enzymatic Hydrolyzate of Chlorophytum Comosum (L.) on AST, ALT and Total Bilirubin Levels}

ALT levels in the blood plasma of rats of the intact group was $2.11 \pm 0.08 \mathrm{IU} / \mathrm{L}$, AST level was equal $1.57 \pm$ $0.013 \mathrm{IU} / \mathrm{L}$. Application of hydrolyzate of Chlorophytum comosum (L.) at toxic liver damage leads to a substantial reduction of ALT $(2.64 \pm 0.1 \mathrm{IU} / \mathrm{L}$ in the control vs $2.21 \pm 0.1 \mathrm{IU} / \mathrm{L}$ in the blood plasma of rats treated with the hydrolyzate $)$ and AST $(2.41 \pm 0.04 \mathrm{IU} / \mathrm{L}$ in control vs 1.68 $\pm 0.10 \mathrm{IU} / \mathrm{L}$ in the blood plasma of rats treated with the hydrolyzate). Total Bilirubin in blood plasma of control rats was $6.71 \pm 0.19 \mathrm{IU} / \mathrm{L}$, bilirubin content in the blood plasma of the experimental group animals decreased to $7.12 \pm 0.10 \mathrm{IU} / \mathrm{L}$ at $13.57 \pm 0.1 \mathrm{IU} / \mathrm{L}$ in the control (Fig. 2).

\subsection{Effects of Enzymatic Hydrolyzate of Chlorophytum Comosum (L.) on Informational Condition of Liver}

The liver of rats of the intact group at the age of two years was characterized by $\mathrm{H}$ equal to $2.627 \pm 0.027$ bits, $\mathrm{S}$ amounted to $0.6926 \pm 0.027 \mathrm{bits}, \mathrm{h}$ is equal to $0.7914 \pm 0.008$ bit, $\mathrm{R}$ amounted to $20.86 \pm 0.83 \%$ (Fig. 3,4 ).

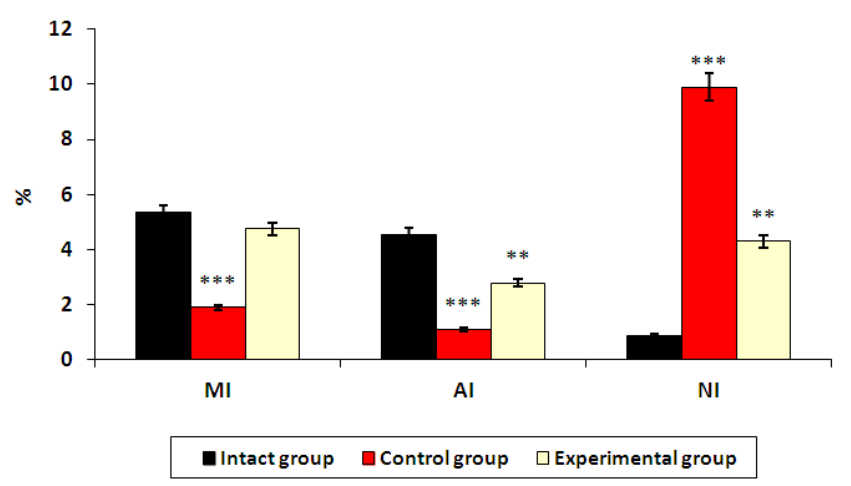

Fig. 1. The value of MI, AI and NI in the liver of rats. Values are significantly different from intact group, (*** indicates $P<0.001$, ** indicates $P<0.01$, * indicates $p<0.05$ ).

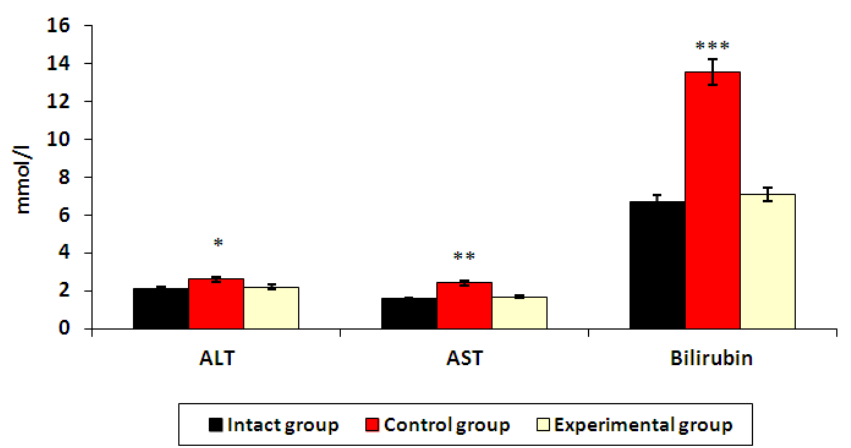

Figure 2. The value of $H, S$ and $h$ in the liver of rats. Values are significantly different from intact group, (*** indicates $P<0.001$, ** indicates $P<0.01$, * indicates $p<0.05$ ).

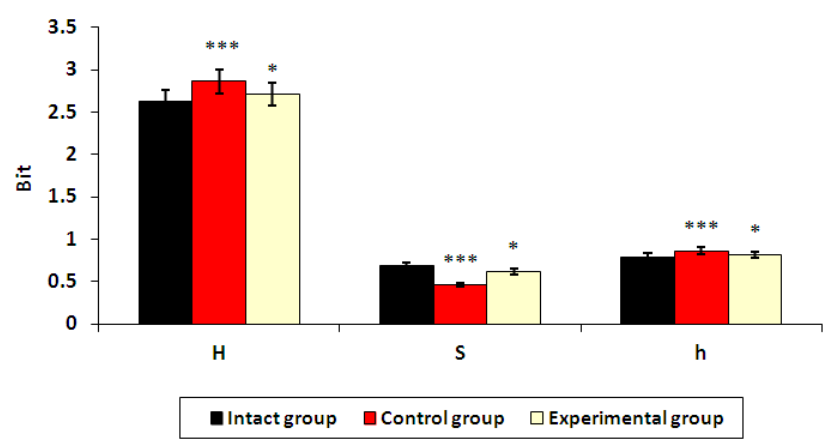

Figure 3. The value of $H, S$ and $h$ in the liver of rats. Values are significantly different from intact group, (*** indicates $P<0.001$, ** indicates $P<0.01$, * indicates $p<0.05$ ). 


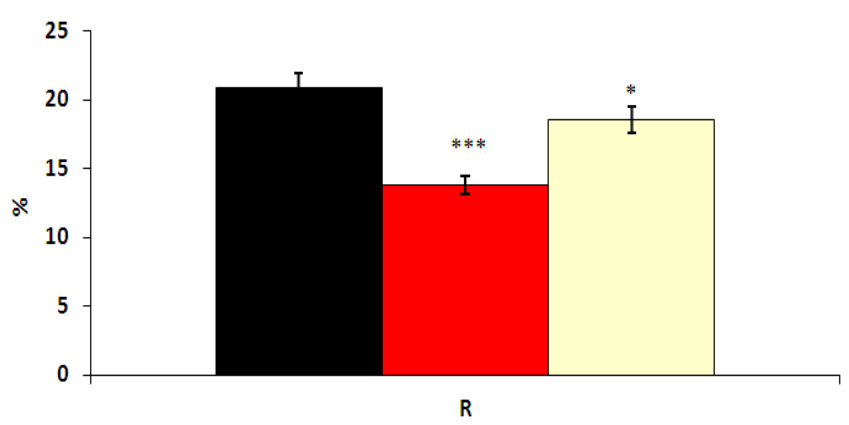

UIntact group $\square$ Controlgroup $\square$ Experimental group

Figure 4. The value of $R$ in the liver of rats. Values are significantly different from intact group, $(* * *$ indicates $P<0.001$, ** indicates $P<0.01$, * indicates $p<0.05$ ).

Information indicators of liver of rats being exposed to $\mathrm{CCl}_{4}$, differ significantly from the age norm. Thus, $\mathrm{H}$ is $2.869 \pm 0.023$ bits, $\mathrm{S}$ is equal to $0.458 \pm 0.023$ bits, $\mathrm{h}-$ $0.8620 \pm 0.007$ bits, $\mathrm{R}-13.81 \pm 0.71 \%$, e amounted to $0,2350 \pm 0,012$ bit.

The liver of rats at the age of two years treated with the enzymatic hydrolyzate in parallel with inhalation $\mathrm{CCl}_{4}$ is characterized by information parameters differ from the livers of rats inhaled carbon tetrachloride. $\mathrm{H}$ was $2.704 \pm 0.026$ bits, $\mathrm{S}$ was $0.6156 \pm 0.026$ bits, $\mathrm{h}$ $0.8146 \pm 0.008$ bits, $\mathrm{R}$ is equal to $18.54 \pm 0.79 \%$, e was $0.091 \pm 0.004$ bit.

\section{Discussion and Conclusions}

The outcome of present investigation undoubtedly indicate that the treatment with enzymatic hydrolizate of Chlorophytum comosum was effective on inhibiting the hepatotoxicity induced by $\mathrm{CCL}_{4}$ in vivo models, most likely because of content of DL - ornithine monohydrochloride or specific constituents present in the hydrolyzate.

Studies suggest that enzymatic hydrolyzate of Chlorophytum comosum has significant hepatoprotective properties, reduces the intensity of the inflammatory process. Hydrolizate has pronounced positive effect on liver regeneration, as evidenced by differences in the mitotic, necrotic, apoptotic index and the proliferation rate in the experimental groups. The liver of rats treated with an enzymatic hydrolyzate of Chlorophytum comosum at toxic damage, based on analysis of the information state of organ, is characterized by a higher level of adaptation and regenerative capacity than the liver of rats of the first experimental group.

The study showed that in contrast to the results obtained under analogous conditions on young rats, studied parameters of liver of rats aged 2 years after applying the enzymatic hydrolyzate though differ significantly from the indices of the control group of rats, as well is significantly different from the indices in intact animals.

We planned to identify more precisely the main components responsible for hepatoprotective activity and to reveal the molecular mechanism of its therapeutic action.

\section{Acknowledgments}

Financial support for this study was provided by Moscow regional state university.

\section{Conflict of interest}

There are no conflicts of interest.

\section{References}

[1] D.A. Areshidze and M.A.Kozlova. The toxity studies of fermentaive hydrolyzate of Clorophytum comosum. Bulletin of the Moscow State Regional University,2009,2; 44-46.

[2] D.A. Areshidze, M.A. Kozlova and T.A. Snisarenko. Characteristics of rat's liver regeneration at the age of three months under the influence of Chlorophytum comosum enzymatic hydrolyzate. Bulletin of the Moscow State Regional University,20011,1; 28-32.

[3] T.H. Arnold and B.C. de Wet. Plants of southern Africa: names and distribution. Memoirs of the Botanical Surveys of South Africa 1993, 62 :968.

[4] S.E. Afton, B. Catron and J.A. Caruso. Elucidating the selenium and arsenic metabolic pathways following exposure to the non-hyperaccumulating Chlorophytum comosum (L.), spider plant. Journal of Experimental Botany 2009, 60; 4;1289-1297.

[5] G.G. Avtandilov. 2008.Medical Morphometry. Meditsina, Moscow. pp.298. [in Russian].

[6] J. Emerit, B. Samuel and N. Pavio. Cu-Zn super oxide dismutase as a potential antifibrotic drug for hepatitis C related fibrosis. Biomedicine \& Pharmacotherapy,2006, 60,$1 ; 1-4$.

[7] M. Giese, U. Bauer-Doranth, S. Langebartels. H. Sandermann. Detoxification of Formaldehyde by the Spider Plant (Chlorophytum comosum (L.) L.) and by Soybean (Glycine $\max$ L.) Cell-Suspension Cultures. Plant Physiology1994,4: 1301-1309.

[8] A.J. Haagen-Smit. E.F. Darley, M. Zaitlin and H. Hull. Noble W. Investigation on injury to plants from air pollution in the Los Angeles area. Plant Physiology, 1952; 27:18-34.

[9] S.N. Hilmer, V.C. Cogger, R. Fraser, A.J. McLean, D. Sullivan and D.G. Le Couteur. Age-related changes in the hepatic sinusoidal endothelium impede lipoprotein transfer in the rat. Hepatology,2005;42: 1349-1354.

[10] G. Hsiao, M.Y. Shen, K.H. Lin, M.H. Lan, L.Y. Wu, D.S. Chou, C.H. Lin, C.H. Su, and J.R. Sheu, Antioxidative and hepatoprotective effects of Antrodia camphorata extract. Journal of Agricultural and Food Chemistry,2005, 51;11: 3302-3308.

[11] C.P. Kala. B.S.Dhyani and B.S. Sajwan. Developing the medicinal plants sector in northern India: challenges and opportunities. Journal of Ethnobiology and Ethnomedicine. 
2006,6: 32-38.

[12] D.G. Le Couteur, V.C. Cogger, R.S. McCuskey, D.E. Cabo, B. Smedsrød, K.K. Sorensen, A. Warren and R. Fraser. Agerelated changes in the liver sinusoidal endothelium: a mechanism for dyslipidemia. Ann N Y Acad Sci. 2007;1114:79-87.

[13] J.E.A. Leakey, H.C. Cunny and J Bazare. Effects of aging and caloric restriction on hepatic drug metabolizing enzymes in the Fisher 344 rat. I: the cytochrome P-450 dependent monooxygenase system. Mechanisms of Ageing and Development.1989;48(2); 145-155.

[14] M.D. Logsdon, Jr. Meyn and P.C .Besa. Apoptosis and the Bcl-2 gene family: patterns of expression and prognostic value in stage I and II follicular center lymphoma? Int $\mathbf{J}$ Radiat Oncol Biol Phys, 1999, 44: 19-29.

[15] H. Matsushita H. Kuwabara, H. Matsushita, S. Ishikawa and M.Mochizuki. Apoptosis Induced in Human Cell Lines by a Butanol Extract from Chlorophytum comosum (L.) Roots. Journal of Health Science, 2005,51: 341-345.

[16] F. Morisco, P.Vitaglione, D. Amoruso, B. Russo, V. Fogliano and N. Caporaso. Foods and liver health. Molecular Aspects of Medicine, 2008, 29,1-2; 144-150.

[17] K. Nagata, H. Suzuki and S. Sakaguchi. Common pathogenic mechanism in development progression of liver injury caused by non-alcoholic or alcoholic steatohepatitis.
The Journal of Toxicological Sciences,2007,32,5; pp. 453 468.

[18] M. Petronijevic and K. Ilic. Associations of gender and age with the reporting of drug-induced hepatic failure: data from the VigiBase ${ }^{\mathrm{TM}}$. J Clin Pharmacol. 2013;53(4);435-443.

[19] D.L. Schmucker. Age-related changes in liver structure and function: Implications for disease ? Exp Gerontol. 2005 Aug-Sep;40(8-9):650-659.

[20] M. Thakur, S. Bhangava and V. Dixit. Immunomodulatory Activity of Chlorophytum borivilianum Sant. Evid Based Complement Alternative Medicine, 2007, 4; 419-423.

[21] K. Jones, L. Timchenko and N.A. Timchenko. The role of CUGBP1 in age-dependent changes of liver functions. Ageing Res Rev. 2012,11(4);442-9.

[22] C.F. van Bezooijen, F.R. de Leeuw-Israel and C.F. Hollander. On the role of hepatic cell ploidy in changes in liver function with age and following partial hepatectomy. Mech Ageing Dev. 1973;1(5);351-6.

[23] R.A. Wood, R. Orwell, M.D. Burchett, J. Tarran, and S.K. Brown Absorption of organic compounds in indoor air by commonly used indoor plants. Proceedings of Healthy Buildings,2000, 2; 125-130. 